\title{
Influence of Restraint on Fire Performance of Reinforced Concrete Columns
}

\author{
T. T. LIE \\ Division of Building Research \\ National Research Council of Canada \\ Ottawa, Ontario, K1A OR6, Canada
}

T. D. LIN

Portland Cement Association

Skokie, Illinois, USA

\section{ABSTRACT}

Experimental and theoretical studies were carried out on the effect of restraint on the fire resistance of reinforced concrete columns. Two tests were carried out on axially loaded columns fully restrained against thermal expansion. Both experimental and theoretical studies indicate that full restraint of axial thermal expansion has little influence on the fire performance of the columns. The maximum stresses in a fully restrained column at the time that the restraining load is maximum, are considerably lower than those at the time of fallure of the column.

\section{INTRODUCTION}

In a fire the expansion of structural members due to heating is often restrained by the integrated surrounding structure. In the case of columns, restraint occurs if the expansion of the column is resisted by the floors above. As a consequence, additional load is imposed on the column; the greater the number of floors above the column, the greater the increase in load. The increase in load may have an adverse effect on the fire resistance of the column.

Theoretical studies [1] indicated that restraint against thermal. expansion of a reinforced concrete column would not significantly affect its fire resistance. Facilities are now available for the testing of columns under restraint and for verification of theoretical results. Such tests have been conducted recently at the National Research Council of Canada as part of a study undertaken in cooperation with the Construction Technology Laboratories of the Portland Cement Association. The results of these tests, and the calculated results, are discussed in the present paper.

\section{MAGNITUDE OF RESTRAINT}

In a previous study [1], the magnitude of restraint was assessed by estimating the vertical stiffness of a floor slab as a function of its dimensions, and by assuming that the total vertical stiffness of the restraining structure is proportional to the number of floors above the column. Depending on the number of floors and their individual vertical stiffness, the magnitude of the restraining forces can vary from close to zero to values close to those present when column expansion is fully restrained. 
In this study two tests were carried out in which the axial expansion of the columns was fully restrained. A full restraint condition was obtained by initially applying the maximum allowable load on the columns and preventing their expansion during the fire tests by controlling the load. The lengths of the columns were kept constant until the load, which increases initially but reduces later with reduction of column strength, had returned to its original value. Then the load was kept constant until the column failed. The maximum a1lowable load was determined according to ACr 318-83 [2], using a live-to-dead load ratio of 0.4 and the actual cylinder strength of the concrete on the test date.

\section{TEST SPECTMENS ${ }^{1}$}

The specimens were square, tied, reinforced concrete columns, made with siliceous aggregate. All were $3810 \mathrm{~mm}$ long and had a cross-section size of $305 \times 305 \mathrm{~mm}$. Twenty-five- $\mathrm{mm}$ diameter longitudinal reinforcing bars and $10 \mathrm{~mm}$ diameter ties were used. The location of the bars, which were welded to steel end plates, and the locations of the ties are shown in Figure 1.

The yield stress of the main reinforcing bars was $444 \mathrm{MPa}$ and that of the ties was $427 \mathrm{MPa}$. The ultimate strength was $730 \mathrm{MPa}$ for the main bars and $671 \mathrm{MPa}$ for the ties.

The designed concrete $\mathrm{mix}$ had a strength of about $35 \mathrm{MPa}$. Its composition per cubic metre was as follows: cement, $325 \mathrm{~kg}$; water, $140 \mathrm{~kg}$; sand, $874 \mathrm{~kg} ;$ coarse aggregate, $1058 \mathrm{~kg}$.

The average compressive cylinder strength of the concrete of the two columns tested, measured on the test dates, was $42.6 \mathrm{MPa}$ for column A and $36.7 \mathrm{MPa}$ for column $\mathrm{B}$. The moisture condition at the center of each column was approximately equivalent to that in equilibrium with aix of $75 \%$ relative humidity at room temperature.

Chrome1-alume1 the mocouples, $0.91 \mathrm{~mm}$ thick, were installed at mid-height of the columns for measuring concrete temperatures at different locations in the cross-section.

\section{CALCULATION PROCEDURE}

The calculation of the fire performance of the columns involves the calculation of temperatures in the column, its deformations, and the stresses in it. The calculation procedure is described in detall in reference 3 . Only a brief description of the method will be given here.

The column temperatures are determined by a finite difference method. The column cross section is divided into a large number of elements. For each element $a$ heat and moisture balance is made. The effect of molsture on temperature is taken into account by assuming that in each element the moisture starts to evaporate when the element temperature reaches $100^{\circ} \mathrm{C}$.

The load on the column during exposure to fire is calculated by a method based on a load-deflection analysis, which in turn is based on a stress-strain analysis of cross sections. In this method, the test columns, which are fixed at the ends during the tests, are idealized as pin-ended columns of reduced

\footnotetext{
${ }^{1}$ Detalled information on the test specimens is avallable.
} 


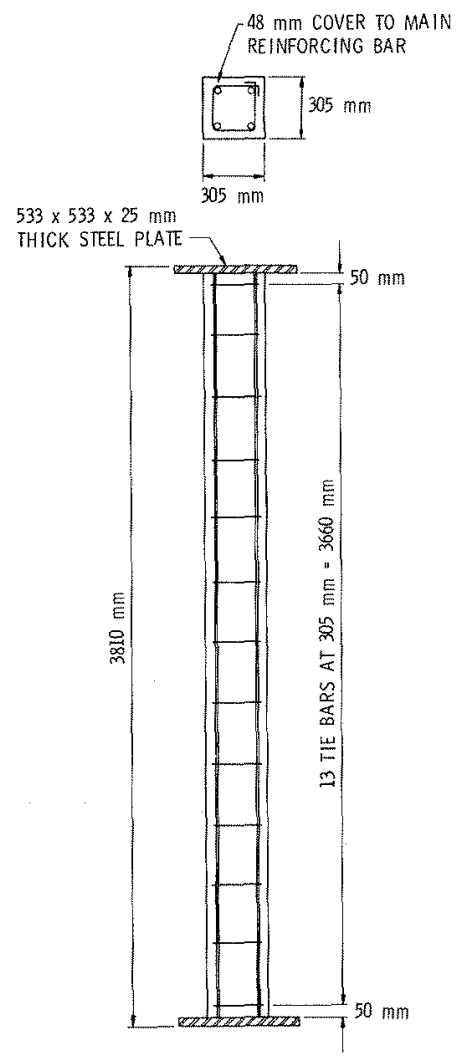

Figure 1. Test column and location of reinforcing bars

effective length, KL (Figure 2), where $\mathrm{K}$ is the effective length factor and $\mathrm{L}$ the unsupported column length. The applied load on the test column is intended to be concentric. To represent imperfections in the column, an initial deflection $\left(\mathrm{y}_{0}\right)$ of $2.5 \mathrm{~mm}$ is assumed.

The curvature of the column is assumed to vary from zero at pin-ends to a maximum at mid-height according to a straight line relation, as illustrated in Figure 2. For any given curvature $x$, and thus for any given deformation, the axial strain is varied until the axial force at mid-section times the deflection is in equilibrium with the internal moment. In this way a load vs axial strain curve can be calculated for specific times during the fire exposure. From these curves the load needed to fully restrain the column can be determined for each time.

In the calculations the material properties of the concrete and steel given in Ref. 3 were used. Stress-strain curves for the concrete and the reinforcing steel used in the calculations are shown in Figures 3 and 4. 


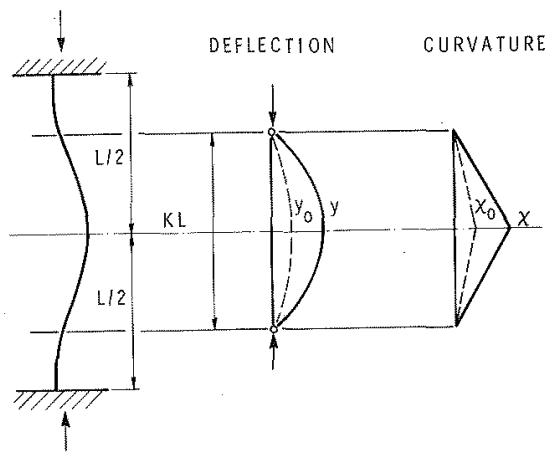

Figure 2. Load-deflection analysis

\section{TEST APPARATUS}

The tests were carried out by exposing the columns to heat in a furnace specially built for the testing of loaded columns and walls. The test furnace was designed to produce the conditions to which a member might be subjected during a fire, with respect to temperature, structural load, and heat transfer. It consists of a steel framework, supported by four steel columns, and the furnace chamber inside the framework. The characteristics and instrumentation of the furnace are described in detail in Ref. 4.

\section{TEST CONDITIONS AND PROCEDURE}

The columns were installed in the test furnace by bolting their steel end-plates to a loading head at the top and a hydraulic jack at the bottom. Concentric loads were applied to the columns about one hour before the fire tests. The load on column $A$ was $1044 \mathrm{kN}$ and that on column $\mathrm{B}, 916 \mathrm{kN}$.

During the tests the heat input into the furnace was controlled so that the average temperature followed as closely as possible the standard temperature-time relation specified in ASTM-E119 [5] or CAN4-S101 [6]. Temperatures in the column were measured at various locations at mid-height.

After application of the load and the start of the fire tests, the lengths of the loaded columns were kept constant by controlling the load. The load increased initially, but decreased later with reduction of the strength of the column. After the load returned to its original value, it was kept constant until the column failed.

The length of each column was measured with differential transducers attached to the furnace frame, one at the bottom level and one at the top level of the column. Inaccuracy in the length measurement due to deformations of the column furnace structural frame, was eliminated by measuring those deformations with strain gauges, and compensating column length accordingly. 


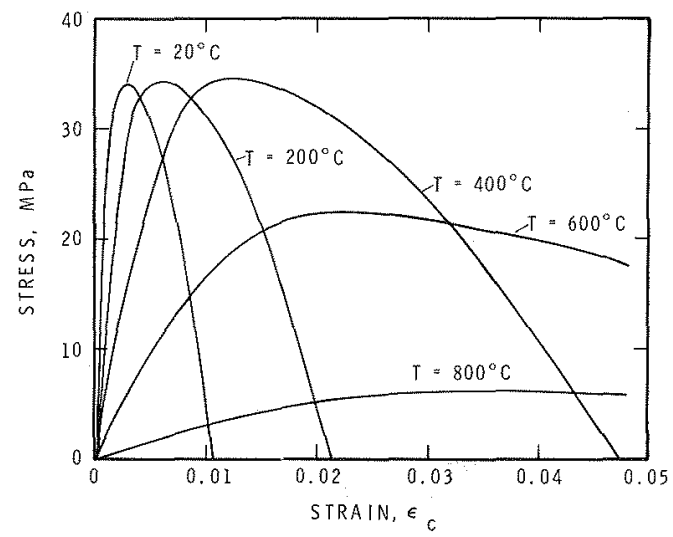

Figure 3. Stress-strain curves for concrete at various temperatures $\left(f_{c o}^{\prime}=35 \mathrm{MPa}\right)$

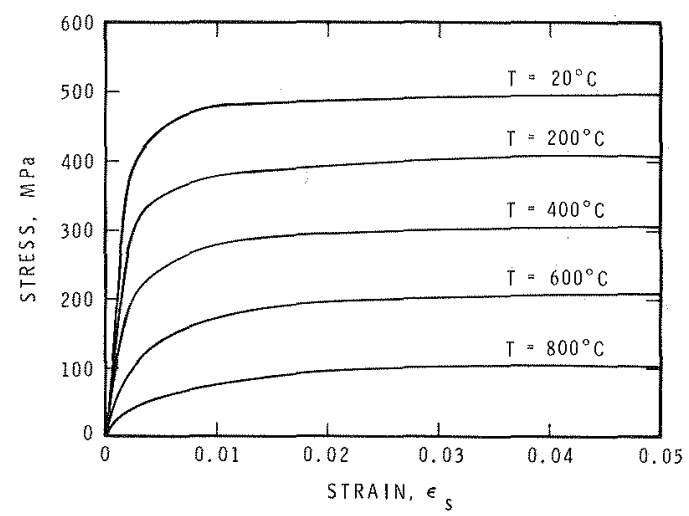

Figure 4. Stress-strain curves for the reinforcing steel at various temperatures ( $\mathrm{f}_{\text {yo }}=443 \mathrm{MPa}$ )

The columns were considered to have failed and the tests were terminated when the hydraulic jack, which had a maxtmum speed of $76 \mathrm{~mm} / \mathrm{min}$, could no longer maintain the applied load.

\section{RESULTS AND DISCUSSION}

\section{Column Temperatures}

Previous studies [3] in which several columns were tested, showed that the mathematical model used for the calculation of temperature in siliceous concrete columns during fire exposure, gives reasonably accurate predictions. 
The columns tested under restraint were made from the same concrete.

Calculated temperatures were again in good agreenent with those measured, as shown in Figure 5. Detalled information on the temperature as a function of depth in similar columns is given in Ref. 3.

\section{Loads and Deformations}

The measured axial applied loads and deformations during the test of columns $A$ and $B$, under full axial restraint, are given in Table 1. Calculated loads to restrain the columns are also given. The measured and calculated loads to restrain the columns, their failure time and the measured axial deformations of the columns during the fire tests are shown in Figure 6 for column $A$, and in Figure 7 for column $B$.

During the test of column $B$, the furnace temperature dropped, after an exposure time of slightly more than $2 \frac{1}{2}$ hours, to below the standard fire temperature for about one half hour, due to power failure. The load on the column was kept above the calculated load by controlling the ram pressure. Because of the interruption, measured and calculated loads are not comparable for column $B$ for the period after $2 \frac{1}{2}$ hour exposure time. For the period up to $2 \frac{1}{2}$ hours in the case of column $B$ and for the entire test period in the case of column $A$, the calculated and measured loads are comparable. For these periods there is a good agreement between calculated and measured loads.

The fallure time of column A was 3 hours 21 minutes. That of column B was 4 hours 2 minutes, or 3 hours 32 minutes, if a conservative correction is made for the power interruption of one-half hour by subtracting 30 minutes from the failure time. The calculated fallure time for both columns was 3 hours 18 minutes. The fallure time of companion columns, tested under comparable loads but unrestrained, averaged 3 hours 33 minutes [3].

The results indicate that full restraint has an insignificant effect on the fire performance of columns. If a column is not subjected to full.

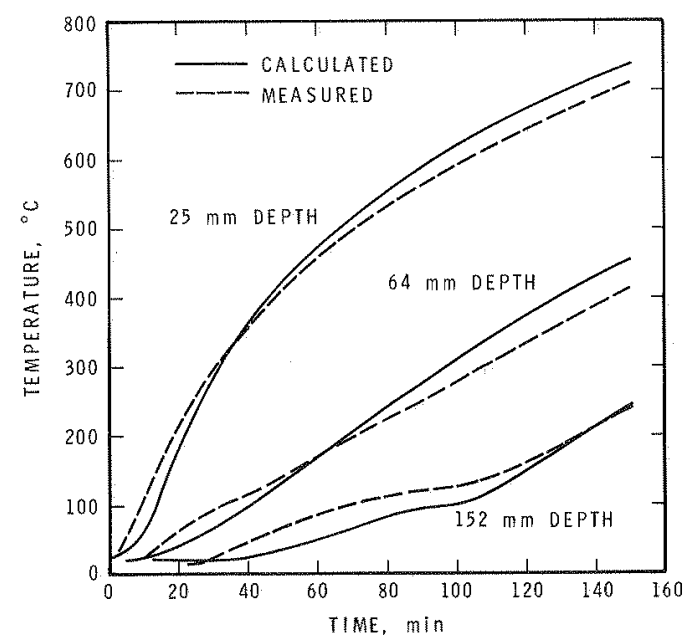

Figure 5. Concrete temperatures in mid-height section along centerline at various depths 
TABLE 1. AXIAL LOADS AND DEFORMATIONS TO FAILURE (COLUMNS A AND B, FULL RESTRAINT)

\begin{tabular}{|c|c|c|c|c|c|c|}
\hline \multirow{3}{*}{$\begin{array}{l}\text { Time } \\
(m i n)\end{array}$} & \multirow{2}{*}{\multicolumn{2}{|c|}{$\begin{array}{c}\text { Axial } \\
\text { deformation (mm) }\end{array}$}} & \multicolumn{4}{|c|}{ Load $(\mathrm{kN})$} \\
\hline & & & \multicolumn{2}{|c|}{ Column A } & \multicolumn{2}{|c|}{ Column B } \\
\hline & Column A & Column $B$ & Measured & Calculated & Measured & Calculated \\
\hline 0 & 0 & 0 & 1044 & 1044 & 916 & 916 \\
\hline 10 & 0 & 0 & 1513 & 1518 & 1410 & 1323 \\
\hline 20 & 0 & 0 & 2049 & 1933 & 1892 & 1702 \\
\hline 30 & 0 & 0 & 1985 & 2240 & 1889 & 1960 \\
\hline 38 & & 0 & & & 1910 & 2067 \\
\hline 40 & 0 & & 1967 & 2313 & & \\
\hline 43 & & 0 & & & 1874 & 2060 \\
\hline 45 & 0 & & 2010 & 2300 & & \\
\hline 50 & 0 & 0 & 1967 & 2282 & 1874 & 2010 \\
\hline 60 & 0 & 0 & 1935 & 2200 & 1878 & 1950 \\
\hline 70 & 0 & 0 & 1892 & 2120 & 1892 & 1890 \\
\hline 80 & 0 & 0 & 1846 & 2042 & 1860 & 1804 \\
\hline 90 & 0 & 0 & 1853 & 1955 & 1832 & 1735 \\
\hline 100 & 0 & 0 & 1767 & 1873 & 1814 & 1649 \\
\hline 110 & 0 & 0 & 1724 & 1792 & 1696 & 1582 \\
\hline 120 & 0 & 0 & 1635 & 1705 & 1649 & 1500 \\
\hline 140 & 0 & 0 & 1413 & 1545 & 1413 & 1349 \\
\hline 150 & 0 & 0 & 1303 & 1452 & 1324 & 1268 \\
\hline 151 & & 0 & & 40 & 1300 & 1260 \\
\hline 160 & 0 & & 1167 & 1365 & & \\
\hline 170 & 0 & & 1044 & 1272 & & \\
\hline 172 & & -0.09 & & & 1120 & 1112 \\
\hline 174 & -0.20 & & 1044 & 1240 & & \\
\hline 178 & -0.57 & & 1044 & 1205 & & \\
\hline 182 & -0.82 & & 1044 & 1170 & & \\
\hline 186 & -1.27 & & 1044 & 1132 & & \\
\hline 190 & -1.81 & & 1044 & 1100 & & \\
\hline 194 & -2.46 & & 1044 & 1062 & & \\
\hline 196 & -2.86 & & 1044 & 1044 & & \\
\hline 197 & & +0.01 & & & 1103 & 916 \\
\hline 198 & -3.27 & & 1044 & 1044 & & \\
\hline 200 & -3.76 & & 1044 & 1044 & & \\
\hline 210 & & 0 & & & 1103 & 916 \\
\hline 220 & & 0 & & & 935 & 916 \\
\hline 225 & & 0 & & & 916 & 916 \\
\hline 230 & & -0.84 & & & 916 & 916 \\
\hline 240 & & -1.80 & & & 916 & 916 \\
\hline 242 & & -5.30 & & & 916 & 916 \\
\hline
\end{tabular}

restraint and the surrounding structure carries some of the load when the column contracts, as is normally the case in practice, restraint is probably beneficlal for the fire performance of the column.

Stresses in Concrete

In Figure 8 calculated stress and temperature distributions in the concrete section are shown for various times: for 45 minutes, when the load 
on the restrained column reaches a maximum, for 120 minutes, and for 198 minutes, when the column would fail. The upper figures give the stress in an element in MPa; the lower figures (in brackets) give the temperature of the element in ${ }^{\circ} \mathrm{C}$. Because the stresses and temperatures are symmetrical with respect to the centerline, only one half of this section is shown.

When the load reaches a maximum at 45 minutes, a maximum stress of about $22 \mathrm{MPa}$ occurs in a region not far from the surface of the column. This stress is about $60 \%$ of the compressive strength of the concrete in this region. The concrete in this region is at temperatures in the range of 300 to $350^{\circ} \mathrm{C}$ and has hardly lost any strength.

As the exposure to fire proceeds, the region of high stresses moves towards the center of the column and the value of the stresses increases. The maximum stress after a two-hour exposure is about $24.5 \mathrm{MPa}$ or $67 \%$ of the compressive strength of the concrete.

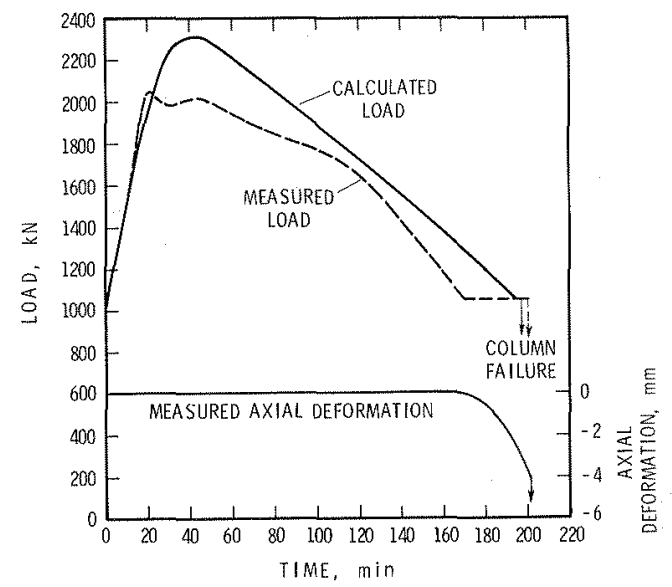

Flgure 6. Loads on column $A$ and its axial deformation under full restraint during fire exposure

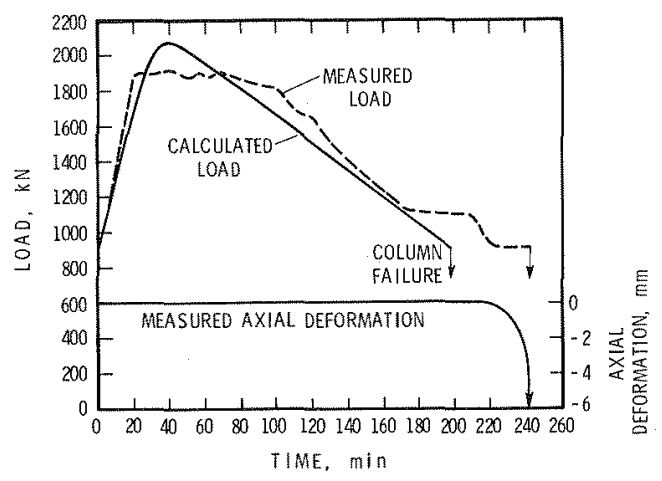

Figure 7. Loads on column $B$ and its axial deformation under full restraint during fire exposure 


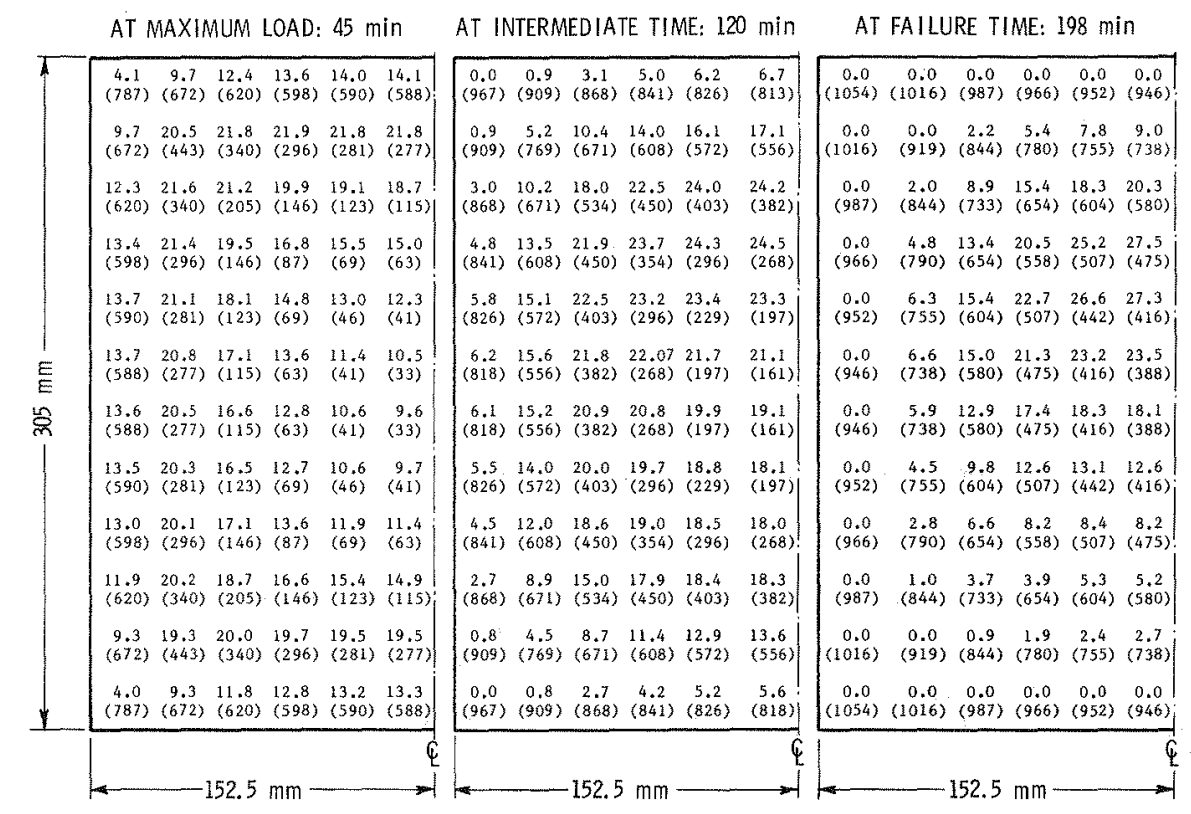

Figure 8. Stresses (upper figure - MPa) and temperatures (lower figure $-{ }^{\circ} \mathrm{C}$ ) in concrete section of restrained column, calculated for various times

The maximum stress continues to increase with the duration of fire exposure. Although the inward movement of the region of high stresses has a delaying effect, the temperature in that region also continues to increase with the duration of exposure. At the time of failure the temperature of the concrete in that region, which lies near the core of the column, will have reached values of $500-600^{\circ} \mathrm{C}$; at this range the compressive strength of the concrete is reduced to about $70 \%$ of its initial strength. At the same time the stresses in that region will have reached the reduced compressive strength of the concrete.

Failure occurs after the load on the restrained column has returned to its initial value, as illustrated in Figure 9. The theoretical failure time and stress distribution in the column at that time are equal to those for an unrestrained column under the same load. In the tests only small

differences in failure time were found between the restrained and unrestrained columns. Thus the additional load to fully restrain the columns did not cause damage or significant permanent deformations in the columns.

\section{CONCLUSIONS}

Experimental and theoretical studies indicate that full restraint of axial thermal expansion of reinforced concrete columns has little influence on the fire performance of the columns. The maximum stress in a fully restrained 


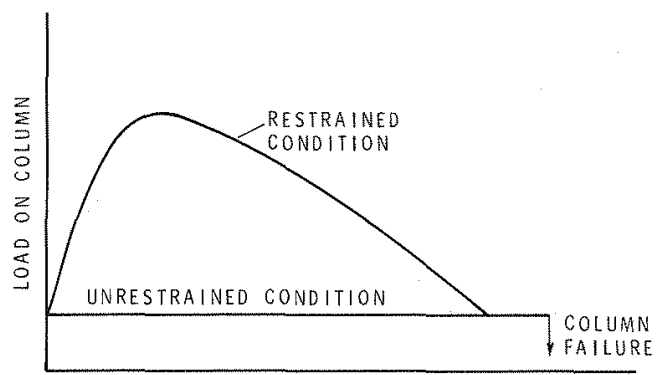

TIME OF EXPOSURE TO FIRE

Figure 9. Loads on a restrained and an unrestrained column during exposure to fire

column when the restraining load is at the maximum is considerably lower than that near the time of failure of the column. The results suggest that restraint of thermal expansion of a relnforced concrete column is beneficial for its fire performance if the surrounding structure is capable of transferring part of the load to other supports, as is normally the case in practice.

\section{REFERENCES}

1. Allen, D.E. and Lie, T.T.: "Further Studies of the Fire Resistance of Reinforced Concrete Columns," National Research Council of Canada, Division of Building Research, DBR Technical Paper 416, NRCC 14047 , Ottawa, 1974.

2. Building Code Requirements for Reinforced Concrete, ACI Standard 318-83, American Concrete Institute, Detroit, 1983.

3. Lie, T.T., Lin, T.D., Allen, D.E. and Abrams, M.S.: "Fire Resistance of Reinforced Concrete Columns," National Research Council of Canada, Division of Butlding Research, DBR Paper 1166, NRCC 23065, Ottawa, 1984.

4. Lie, T.T.: "New Facility to Determine Fire Resistance of Columns," Canadian Journal of Civil Engineering, 7: 3, 551-558, 1980.

5. Standard Methods of Fire Tests of Building Construction and Materials, ANSI/ASTM E119-83, American Society for Testing and Materials, Philadelphia, $\mathrm{Pa}, 1983$.

6. Standard Methods of Fire Endurance Tests of Building Construction and Materials, CAN4-S101-M82, Underwriters' Laboratories of Canada, Scarborough, Ontario, 1982 . 